\title{
Theory and design of an experimental intelligent plant for regulating plant productivity
}

\author{
Dmitry Polenov* and Alexey Belyi \\ Mytischi Branch of Bauman Moscow State Technical University, 141005 1st Institutskaya street, 1, \\ Mytischi, Moscow region, Russia
}

\begin{abstract}
The article proposes to regulate the values of factors affecting the productivity of plants using an artificial intelligence device, the main element of which is a mathematical neuron. The installation is adaptive to the growing area of the investigated plant object. This increases its efficiency and increases the importance of plant productivity. A block diagram of the experimental setup, a general block diagram of the setup control algorithms have been developed, one of the options for using the experimental setup as a research system for identifying the most significant combinations of factors affecting plant productivity has been considered. To identify the most significant combinations of factors, algorithms based on generalized training algorithms for the Hebb neural network model were used, and a study was made of a model of an installation of four inputs with sigmoidal transfer functions.
\end{abstract}

Research papers, devoted to the analysis of ways to achieve maximum plant productivity, regulation of factors affecting it, as a rule, usually analyze:

1) soil properties;

2) the required amount of irrigation;

3) values of temperature, humidity of the environment;

4) soil moisture values;

5) other questions.

There are known works on the studies carried out on the regulation of productivity factors and their compensation by other factors. There are substitutions of natural factors for artificial ones, research is being conducted:

1) the dependence of plant photosynthesis on lighting;

2) the relationship between the rate of photosynthesis and ambient temperature;

3) correlations of productivity from standing density;

4) relationship of assimilators on the volume of irrigation, ambient temperature;

5) conditionality of the required level of water consumption at different phases of plant flowering.

These studies are aimed at increasing the productivity of plants - the most important task determined by the timely provision of food to the population.

\footnotetext{
${ }^{*}$ Corresponding author: polenoff.mitya@yandex.ru
} 
In addition to carrying out these studies of productivity growth, attention is paid to the methods of its assessment and forecasting. For this, accurate data on cultivated areas, weather forecasts, climate, lighting, etc. are analyzed. Such indicators also include the intensity of solar radiation, the intensity of reflection of sunlight, etc.

In addition, it should be noted that the same plant object growing in different regions/districts/countries with the same regulation of productivity factors can show different values. Because it is impossible to take into account all the factors affecting productivity. It is necessary to conduct research on obtaining the maximum productivity of plants precisely in the places of their growth. This imposes additional restrictions on research.

These productivity factors can be regulated by introducing automated means into the agricultural sector, the analysis of which is also necessary. Automation of agricultural complexes is closely related to research into the implementation of plant productivity programming [1 - 3]. When automation is introduced, it is necessary to analyze the consumption of additional energy to obtain a unit of energy contained in human food. In the process of conducting research, one should understand: is it worth automating the agricultural sector, to what extent, to what extent? After all, you can spend more energy than will be in the resulting product, and the efficiency will be minimal.

Regulation of productivity factors can be done using artificial intelligence [4]. Artificial intelligence systems are widely implemented in various sectors of the national economy [5 7]. As you know, systems containing artificial intelligence can collect data (or they are previously entered into the database), process them and make decisions based on them [4, 8]. In this case, data on the dependences of productivity on factors can be entered into such a database. Robotics is also involved in the analysis and regulation of plant productivity factors [9]. In addition, the database can be constantly replenished by obtaining information about the obtained productivity of plants for the reporting period with known values of productivity factors, that is, to have feedback. Based on the foregoing, the installation will acquire the status of intellectual.

The foregoing allows us to conclude that the productivity of plants is affected by a huge number of factors, one part of which can be regulated by creating automated control systems, the second part can be compensated by replacing some factors with others [10], the third one can be measured and taken into account as given, etc.

All this makes it possible to formulate the goal of the study - to achieve the maximum productivity of plants, taking into account the known dependences of the factors influencing it, the presence of automated means of controlling factors, the place of growth of the plant object under study. To achieve it, it is proposed to develop an appropriate experimental setup, which will have the following features:

1) contain sensors that show the state of various factors (illumination, temperature, humidity, environment, soil features, etc.);

2) include actuators that allow you to control some factors of plant productivity (pumps, filters, heating devices, etc.). At the same time, the installation should be universal - it should be able to regulate from one to several factors affecting the productivity of plants;

3) an information input device required to enter data on the dependences of productivity on factors affecting it, the knowledge of experts, the productivity obtained for the reporting period, etc.;

4) be in the place of growth of the investigated object.

The structural scheme of the experimental intelligent installation being developed is shown in Figure 1. 


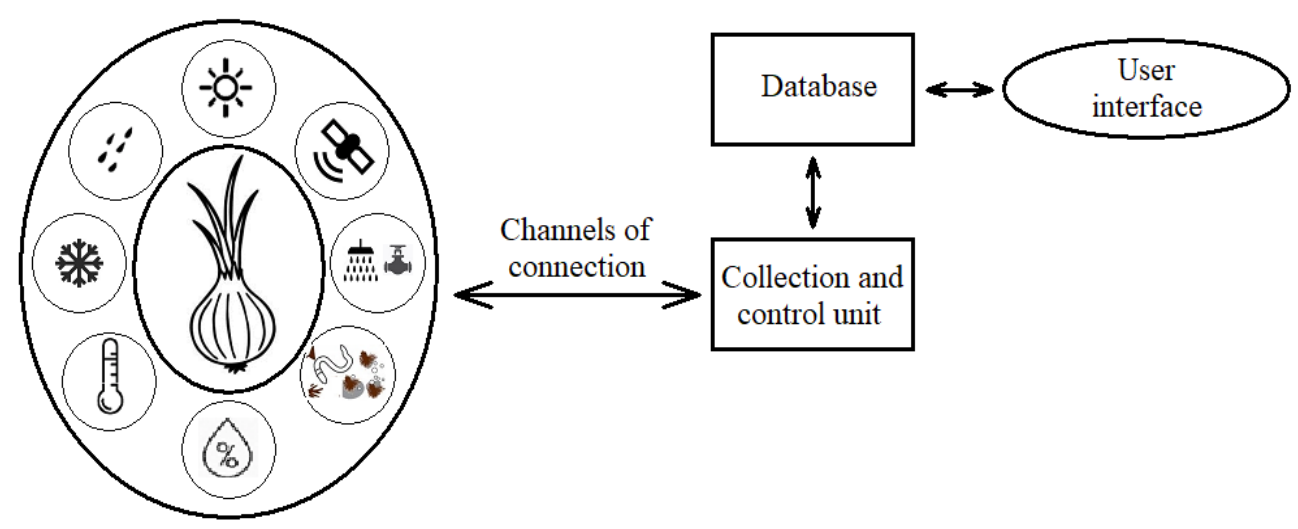

Fig. 1. Structural scheme of an experimental intelligent installation.

The core of the experimental intelligent installation is a collection and control unit $(\mathrm{CCU})$, which receives information from sensors of humidity, soil and environmental temperature, pressure, illumination, soil composition, etc., which monitor all kinds of factors affecting plant productivity. In addition, the CCU processes information from the satellites of the Hydrometeorological Center about the weather forecast, the approaching precipitation and controls various actuators of the installation - electromagnetic valves of the water supply system, a pump relay, etc. The CCU interacts with the specified devices and systems by means of wired (RS-485 interface, Ethernet technology, etc.) and wireless communication channels (Bluetooth, Wi-Fi, GSM, etc.). A Database is connected to the $\mathrm{CCU}$, storing the knowledge of experts, the dependence of plant productivity on factors influencing it. To enter and correct information in the database, there is a User interface - a specialized set of programs that implement the user's dialogue with the installation.

The experimental setup is intelligent. The management of the executive mechanisms that regulate the factors of plant productivity is carried out after processing the information originally entered in the database and the productivity obtained for the reporting period. The main element of the artificial intelligence of the installation is a mathematical neuron, similar to Rosenblatt's perceptron [11]. Signals from $n$ sensors tracking the states of productivity factors are fed to its inputs $x_{n}$, output $y$ is presented as a command for the corresponding actuator of the installation. Output $y$ can take values « $0 »$ or « $1 »$. It depends on the input $x_{n}$ values of the factors and the obtained productivity of plants [12].

These features will make it possible to make the experimental setup adaptive to the growing area of the studied plant object. This will increase the efficiency of the installation and increase the value of productivity, which means that it will allow achieving the formulated goal - to achieve maximum plant productivity, taking into account the above factors and the place of growth of the studied plant object.

The basic version of the system contains algorithms, the general functional diagram of which is shown in Figure 2.

The neural network structure consists of input $(x)$, output $(z)$ and intermediate (hidden) layers $(y, k)$. The nodes of the network are interconnected by weight coefficients $w$, which, when training the system, become, in fact, the weight functions of the input and output parameters of the layer. 


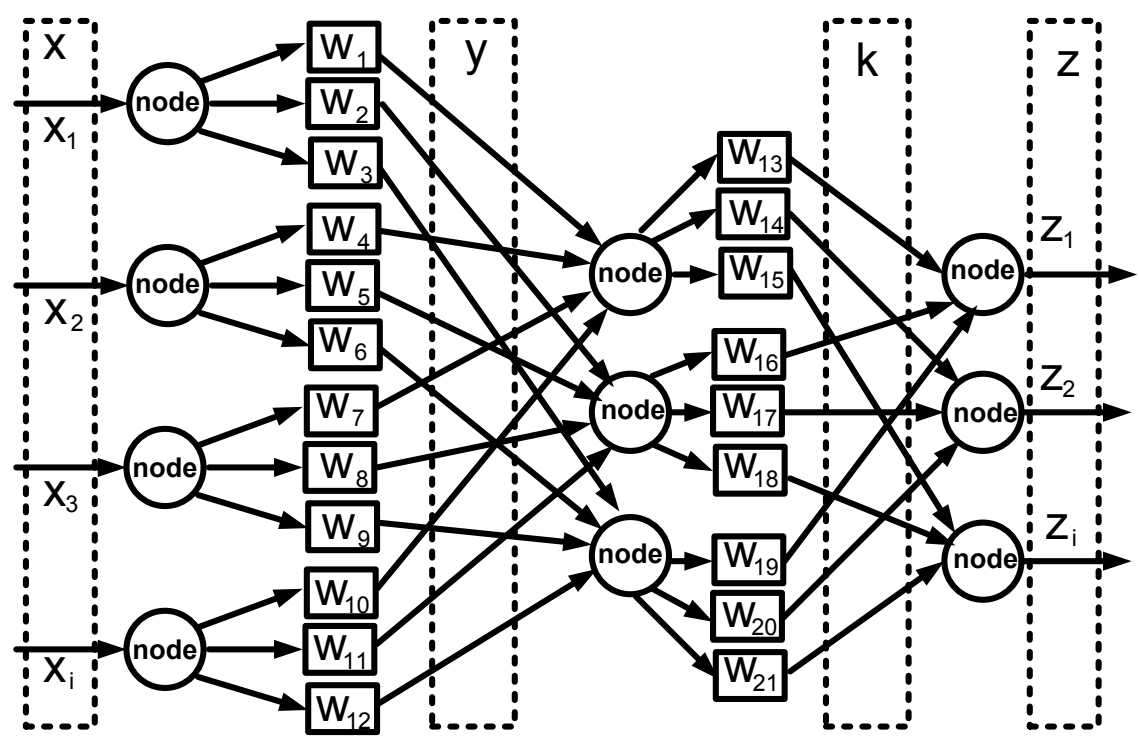

Fig. 2. General structural scheme of control algorithms

As an example, we consider one of the options for using the experimental setup as a research system to identify the most significant combinations of factors affecting plant productivity. In this case, it is advisable to use algorithms based on generalized learning algorithms for the Hebb neural network model. A feature of the implementation of the control system is its versatility in terms of programming, since this system can be implemented in any programming language of industrial controllers, including graphic ones.

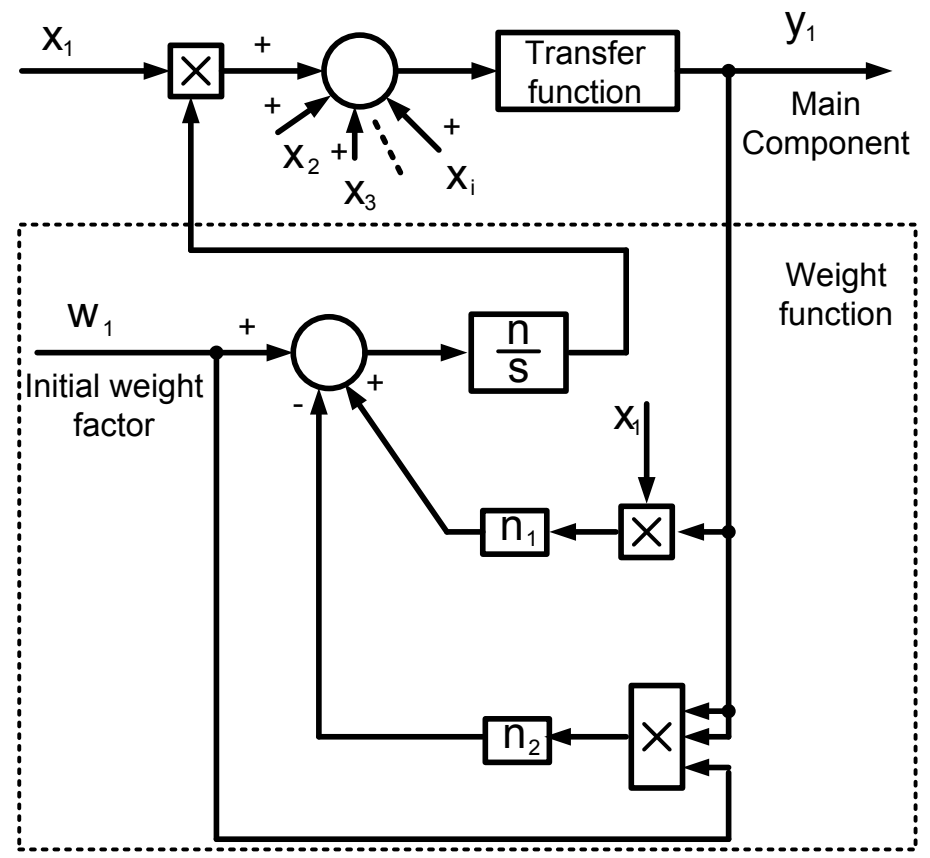

Fig. 3. Fragment of the structural diagram of the algorithm for identifying the latent factor. 
This feature is important when implementing a local subsystem for studying a group of factors, remote from the main computing node. Such a local subsystem requires an increased degree of weather protection and, as a rule, has a relatively low computing power.

Figure 3 shows an example of a block diagram of the algorithm for identifying the main latent factor that affects the objective function.

Figure 3 shows the first node of the neural network model. The $W_{l}$ weighting factor has been transformed into a weight function and is only used to set the initial value. The weighting function depends on the values of the input factor $x_{1}$ and the output value of the node $y_{l}$ and is implemented on the basis of the neuron learning rule Oja. In this algorithm, a transition to the time domain is carried out using the integration operation with the possibility of stopping it. The neuron learning rate in this case is characterized by the coefficient $n$. The coefficients $n_{1}$ and $n_{2}$ ensure the convergence of the weight function. The transfer function of a node can be a sigmoidal function or a relay function with a logic output.

The study of the structure of Figure 3 was carried out in the Matlab environment on a model of four inputs (Figure 2) with sigmoidal transfer functions. The results of the output signal $y_{l}$ when training the model are shown in Figure 4 . The minimum root-mean-square error is $10^{-10}$. For a control error of less than $10^{-8}, 20$ iterations are sufficient.

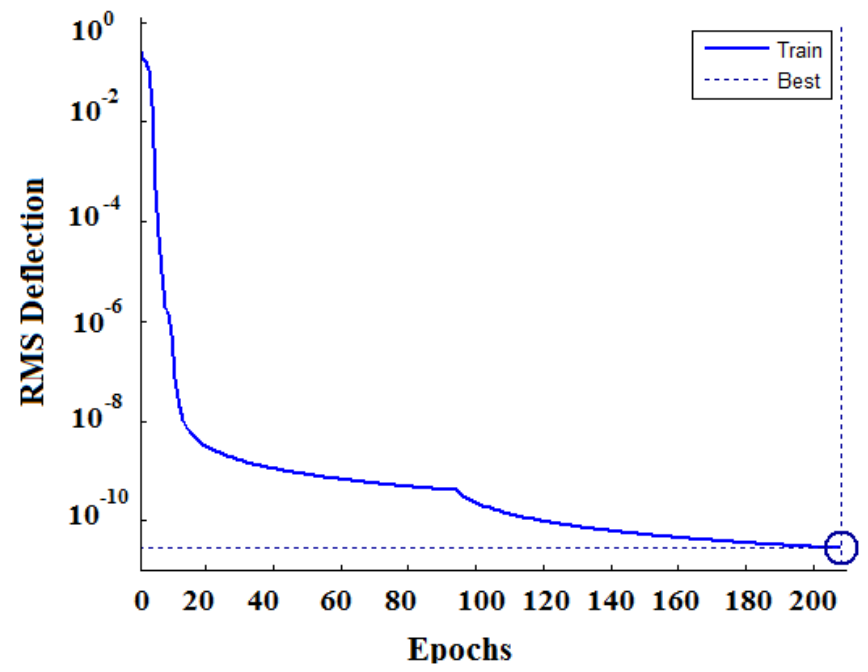

Fig. 4. Model training results.

\section{Conclusions}

1) It is proposed to regulate the values of the factors influencing the productivity of plants using an installation with artificial intelligence, the main element of which will be a mathematical neuron. In this case, the installation is adaptive to the growing area of the investigated plant object. This will increase the efficiency of the plant and increase the importance of plant productivity;

2) a block diagram of the experimental setup has been developed, the core of which is an acquisition and control unit, to which sensors and a system database with a developed user interface are connected using wired and wireless communication channels;

3) a general block diagram of the installation control algorithms has been developed, the neural network structure of which consists of input, output and intermediate layers; 
4) one of the options for using the experimental setup as a research system for identifying the most significant combinations of factors influencing the productivity of plants is considered. Algorithms based on generalized learning algorithms for the Hebb neural network model are applied;

5) the study of the model of the installation of four inputs with sigmoidal transfer functions was carried out. It is shown that the minimum root-mean-square error is $10^{-10}$, and for the control error (less than $10^{-8}$ ) 20 iterations are sufficient.

\section{References}

1. G. Bazdyrev, V. Loshakov, A. Puponin, Zemledelie, p. 24 (2000).

2. M. K. Kayumov, Spravochnik. Programmirovaniye produktivnosti polevykh kul'tur, 368 p. (1989).

3. N. Mozhaev, P. Serikpayev, G. Stybaev, Programming of agricultural crops: a textbook, 160 p. (2013).

4. D.F. Luger Artificial Intelligence. Strategies and methods for solving complex problems, 864 p. (2005).

5. A.Ross, Industries of the future, p. 4 (2017).

6. E. Siegel, Calculate the future. Who clicks, buys, lies or dies, p. 5 (2018).

7. K. M. Schwab, The fourth industrial revolution, 288 p. (2017).

8. N. Bostrom, Artificial intelligence. Stages. Threats. Strategies, 496 p., (2016).

9. S. V.Shanygin, Roboty kak sredstvo mekhanizatsii sel'skogo khozyaystva, Izv. vyssh. ucheb. zavedeniy. Mashinostroyeniye, v 3. pp. 39-42 (2013).

10. D. Yu. Polenov, Sistema intellektual'nogo upravleniya vodosnabzheniyem ob"yektov rasteniyevodstva, Zhurnal «Informatsionno-tekhnologicheskiy vestnik», v 4 (22), pp. 91 - 97 (2019).

11. F. Rosenblatt, The perseptron: a probalistic model for information storage and organization in the brain, Psychological Review, v 65 (1958).

12. D. Yu. Polenov, Artifical intelligence of the water supply system of plant growing objects, IOP Conference Series: Materials Science and Engineering. 6 Cep. $\ll 20196^{\text {th }}$ International Conference on Advanced Materials, Mechanics and Structural Engineering» (2020). 